\title{
Commentary \\ Heparin-induced thrombocytopenia during renal replacement therapy in the intensive care unit
}

Andrew Davenport

Royal Free and University College Medical School, UCL Centre for Nephrology, Hampstead Campus, Rowland Hill Street, London NW3 2PF, UK

Corresponding author: Andrew Davenport, Andrew.Davenport@royalfree.nhs.uk

Published: 30 June 2008

This article is online at http://ccforum.com/content/12/3/158

(c) 2008 BioMed Central Ltd

See related research by Lasocki et al., http://ccforum.com/content/12/3/R84
Critical Care 2008, 12:158 (doi:10.1186/cc6914)

\begin{abstract}
Whereas some $30 \%$ to $50 \%$ of patients admitted to the intensive care unit develop thrombocytopenia during their stay, the incidence of heparin-induced thrombocytopenia (HIT) remains low, at around $0.3 \%$ to $0.5 \%$. Lasocki and colleagues prospectively tested patients with premature clotting of the hemofiltration circuit for HIT, and reported a $25 \%$ incidence of HIT, particularly if the circuit clotted within 6 hours. By switching the anticoagulant from heparin to danaparoid, the hemofiltration circuit survival and urea clearances improved. HIT should therefore be clinically suspected if extracorporeal circuits clot repeatedly.
\end{abstract}

The diagnosis of heparin-induced thrombocytopenia (HIT) depends upon clinical suspicion and laboratory testing. Unfortunately only a limited number of laboratories in the world are now capable of performing the gold-standard platelet serotonin release assay to determine whether the antibodies are pathogenic. Most laboratories, as with Lasocki and colleagues [1], therefore rely on commercially available enzyme immunoassays (EIAs) - which have a high sensitivity due to a high negative predictive value, but have variable specificity as they also detect $\lg \mathrm{A}$ and $\lg \mathrm{M}$ antibodies, which are probably not pathogenic [2]. Functional assays of platelet aggregation are therefore often used to confirm EIA results.

Heparin binds to surface-bound platelet factor 4 (PF4) and, although used as an anticoagulant, paradoxically causes platelet activation. When patients are first exposed to heparins, therefore, typically there is a mild fall in the peripheral platelet count [3]. If patients are exposed to a critical amount of heparin, a stoichiometric ratio of $27 \mathrm{IU}$ heparin to $1 \mathrm{mg}$ PF4, then cross-linking of surface-bound PF4 leads to conformational change and to the exposure of novel epitopes, with the potential to form pathogenic $\operatorname{lgG}_{1}$ antibodies to the heparin/PF4 complex. Fortunately, the incidence of HIT remains low in the intensive care unit $(0.3 \%$ to
$0.5 \%$ [4], probably because most patients do not receive sufficient heparin to achieve the critical ratio to lead to novel epitope exposure. Using an initial priming solution containing 10,000 IU heparin, followed by a heparin infusion, may therefore have accounted for the increased incidence of HIT (8\%) reported [4]. Heparin/PF4 antibodies occur most commonly following cardiac and vascular surgery, when patients receive large doses of heparin intraoperatively [5].

The clinical sequalae of developing heparin/PF4 antibodies detected by EIA varies widely [6] - ranging from being totally asymptomatic to repeated clotting of the extracorporeal circuit [7], to increased venous thrombosis at the sites of indwelling central venous catheters [8], and to sudden collapse due to pulmonary emboli or pseudopulmonary embolus syndrome following intravenous heparin administration [9].

This disparity between the detection of heparin/PF4 antibodies by EIA and the clinical sequalae has led to the concept of separating HIT from heparin-induced thrombocytopenia and thrombosis (HITTS), and some authors have questioned the reliability of EIAs in detecting pathologically relevant antibodies [2]. EIA optical density results have been compared recently with the gold-standard platelet serotonin release; taking a 50\% serotonin release as a positive heparin/PF4 antibody result, this corresponded to an EIA optical density $\geq 1.4$ [10]. Even so, in Lasocki and colleagues' study, the optical density EIA results were not greater in the two patients with thrombotic complications, and there was no correlation between EIA results within the HIT-positive group with thrombocytopenia or circuit clotting [1]. Heparin administration and dosing, and also the presence of other antibodies - including those directed to platelet cytokines and other surface receptors - and platelet activation may therefore be important in determining clinical outcomes.

$\mathrm{EIA}=$ enzyme immunoassay; HIT = heparin-induced thrombocytopenia; PF4 = platelet factor 4. 
Table 1

The 4T (thrombocytopenia, timing, thrombosis, and other causes) pretest probability of heparin-induced thrombocytopenia [6]

\begin{tabular}{|c|c|c|c|}
\hline & \multicolumn{3}{|c|}{ Score } \\
\hline & 2 & 1 & 0 \\
\hline Acute thrombocytopenia & $\begin{array}{l}20 \text { to } 100 \times 10^{9} / / \text {, at least } 30 \% \text {, } \\
\text { or any } 50 \% \text { fall }\end{array}$ & $\begin{array}{l}10 \text { to } 19 \times 10^{9} / \mathrm{l} \text {, any } 30 \% \text { to } \\
50 \% \text { fall, or }>50 \% \text { fall post } \\
\text { cardiac surgery }\end{array}$ & $<10 \times 10^{9} / \mathrm{l}$, or any $<30 \%$ fall \\
\hline $\begin{array}{l}\text { Timing of fall in platelet count or } \\
\text { thrombosis or other sequalae }\end{array}$ & $\begin{array}{l}\text { Clearly } 5 \text { to } 10 \text { days (or } \leq 1 \text { day } \\
\text { if previous heparin given for } \\
<30 \text { days) }\end{array}$ & $\begin{array}{l}5 \text { to } 10 \text { days but not clear (or } \\
\leq 1 \text { day if previous heparin for } \\
31 \text { to } 100 \text { days), or }>10 \text { days }\end{array}$ & $\begin{array}{l}\leq 4 \text { days, with no prior heparin } \\
\text { exposure }\end{array}$ \\
\hline $\begin{array}{l}\text { Thrombosis or other clinical } \\
\text { sequalae }\end{array}$ & $\begin{array}{l}\text { New thrombosis, skin necrosis, } \\
\text { or acute systemic reaction } \\
\text { post intravenous bolus }\end{array}$ & $\begin{array}{l}\text { Progressive or recurrent } \\
\text { thrombosis, erythematous } \\
\text { skin lesions }\end{array}$ & None \\
\hline Other cause for thrombocytopenia & No other explanation & Possible other cause evident & Definite other cause present \\
\hline
\end{tabular}

High total score, 6 to 8 (HIT very likely); intermediate total score, 4 to 5 ; and low total score 0 to 3 . Timing $=$ first day of exposure to heparin, counted as day 0 .

Once HIT is clinically suspected it is imperative that all heparin administration is withdrawn [11], including heparin catheter locks and flushes [9], and another systemic anticoagulant is substituted [12]. Patients in this series were successfully anticoagulated with danaparoid [12], and not only did hemofilter circuit survival increase but so did urea clearances. This observation would suggest that the patients with HIT had increased platelet and thrombus deposition within the hemofilter, therefore causing membrane fouling and reduced clearances [13]. Interestingly, circuit survival and clearances were better for the HIT-positive group anticoagulated with danaparoid, compared with the HITnegative group who remained on heparin. This difference may have been due to so-called heparin resistance associated with reduced antithrombin in the HIT-negative patient group.

The increased incidence of EIA heparin/PF4 antibodies reported in the present study was probably due to the larger doses of heparin used in priming the hemofilter circuit, and heparin exposure should therefore be minimised in the intensive care unit to reduce the incidence of HIT. The 4T (thrombocytopenia, timing, thrombosis, and other causes) pre-test probability scoring system did not predict which patients with early hemofiltration circuit clotting subsequently had positive EIA tests for HIT antibodies (Table 1). Whereas previous patient series have suggested early circuit clotting was associated with vascular access problems, the present study showed that heparin/PF4 antibodies caused clotting within the hemofilter, and that danaparoid was a more effective extracorporeal anticoagulant than heparin in the HITnegative group. HIT should therefore be considered in cases of very early or repeated circuit clotting.

\section{Competing interests}

$A D$ has received travel bursaries to attend international scientific meetings from Orgaron.

\section{References}

1. Lasocki S, Piednoir P, Ajzenberg N, Geffroy A, Benbara A, Montravers P: Anti-PF4/heparin antibodies associated with repeated hemofiltration-filter clotting: a retrospective study. Crit Care 2008, 12:R84.

2. Parker Rl: Measurement of heparin dependent platelet antibodies in the diagnosis of heparin induced thrombocytopenia: fact or fiction? Crit Care Med 2007, 35:1784-1785.

3. Davenport A: Heparin induced thrombocytopenia during renal replacement therapy. Hemodial Int 2004, 8:295-303.

4. Selleng K, Warkentin TE, Greinacher A: Heparin induced thrombocytopenia in intensive care unit patients. Crit Care Med 2007, 35:1165-1176.

5. Charif R, Davenport A: Heparin-induced thrombocytopenia: an uncommon but serious complication of heparin use in renal replacement therapy. Hemodial Int 2006, 10:235-240.

6. Warkentin TE: Clinical picture of heparin induced thrombocytopenia. In Heparin Induced Thrombocytopenia. Edited by Warkentin TE, Greinacher A. 3rd edition. Basel: Marcel Dekker Inc.; 2004:53-106.

7. Davenport A: Management of heparin-induced thrombocytopenia during continuous renal replacement therapy. $\mathrm{Am} J$ Kidney Dis 1998, 32:e1-e5.

8. Hung AP, Cook DJ, Sigouin CS: Central venous catheters and upper extremity deep venous thrombosis complicating heparin induced thrombocytopenia. Blood 2003, 101:30493051.

9. Davenport A: Sudden collapse during haemodialysis due to immune mediated heparin induced thrombocytopenia. Nephrol Dial Transplant 2006, 21:1721-1724.

10. Warkentin TE, Sheppard JI, Moore JC, Sigouin CS, Kelton JG: The quantitative interpretation of optical density measurements using PF4 dependent enzyme immunoassays. J Thromb Haemost May 172008 [Epub ahead of print].

11. Davenport A: Intradialytic complications during haemodialysis. Hemodial Int 2006, 10:162-167.

12. Keeling $D$, Davidson $S$, Watson $H$, on behalf of the Hemostasis and Thrombosis Task Force of the British Committee for Standards in Hematology: The management of heparin induced thrombocytopenia. Br J Haemato/ 2006, 133:259-269.

13. Davenport $A$ : Anticoagulation options for patients with heparin-induced thrombocytopenia requiring renal support in the intensive care unit. Contrib Nephrol 2007, 156:259-266. 